\title{
Neighborhood frequency effects and letter visibility in visual word recognition
}

\author{
JONATHAN GRAINGER, J. KEVIN O'REGAN, ARTHUR M. JACOBS, and JUAN SEGUI \\ Laboratory of Experimental Psychology, CNRS, and René Descartes University, Paris, France
}

\begin{abstract}
Two experiments are described that measured lexical decision latencies and errors to five-letter French words with a single higher frequency orthographic neighbor and control words with no higher frequency neighbors. The higher frequency neighbor differed from the stimulus word by either the second letter (e.g., ASTRE-AUTRE) or the fourth letter (CHOPE-CHOSE). Neighborhood frequency effects were found to interact with this factor, and significant interference was observed only to cHOPE-type words. The effects of neighborhood frequency were also found to interact with the position of initial fixation in the stimulus word (either the second letter or the fourth letter). Interference was greatly reduced when the initial fixation was on the critical disambiguating letter (i.e., the letter $P$ in CHOPE). Moreover, word recognition was improved when subjects initially fixated the second letter relative to when they initially fixated the fourth letter of a fiveletter word, but this second-letter advantage practically disappeared when the stimulus differed from a more frequent word by its fourth letter. The results are interpreted in terms of the interaction between visual and lexical factors in visual word recognition.
\end{abstract}

Recent research in visual word recognition has demonstrated that words that are orthographically similar to a more frequent word are harder to recognize than are words that do not have such higher frequency orthographic neighbors (Grainger, 1990; Grainger, O'Regan, Jacobs, \& Segui, 1989; Grainger \& Segui, 1990). Comparable results have also been reported with respect to the effects of phonological neighborhoods in auditory word recognition (Luce, 1986; Luce, Pisoni, \& Goldinger, 1990). The basic result, referred to as the neighborhood frequency effect, suggests that these higher frequency orthographically similar words are strongly activated on presentation of the stimulus word and subsequently interfere in the recognition of this word.

Activation-based models of visual word recognition can explain the observed interference in terms of the mechanism they invoke to select the stimulus word representation from the set of candidates activated by the stimulus input. In the activation-verification model (Paap, Newsome, McDonald, \& Schvaneveldt, 1982), a word's orthographic neighbors will figure in the set of candidates to be submitted to a frequency-ordered verification process. Recognition latencies will depend on the stimulus word's position in this candidate set. The higher frequency neighbors of the stimulus will be checked before the stimulus word itself, thus incurring a delay in recognition relative to stimulus words

\footnotetext{
The authors wish to thank Maria del Mar Alonso for her help in the preparation and running of the experiments reported here. We would also like to thank Lester Krueger and three anonymous reviewers for their helpful comments on an earlier version of this article. Correspondence concerning this article may be addressed to Jonathan Grainger at the Laboratoire de Psychologie Experimentale, 28 rue Serpente, 75006 Paris, France.
}

that do not have higher frequency neighbors. In a recent modification of the activation-verification model (Grainger \& Segui, 1990, 1991; Segui \& Grainger, 1990), word frequency determines the resting level activation of word nodes and checking order is a function of activation level. Thus, the more activated a competing node is, the more likely it will be checked before the stimulus word. This modification allows the activation-verification model to accommodate recent results on neighborhood frequency and orthographic priming (for a discussion of this modification, see Grainger \& Segui, 1990; Segui \& Grainger, 1990).

The interactive-activation model (McClelland \& Rumelhart, 1981), on the other hand, explains the neighborhood frequency effect in terms of mutually inhibitory connections between lexical representations. Every activated word unit inhibits all other word units, and the degree of inhibition depends on the activation level of the inhibiting unit. Thus, the stimulus word node will inhibit and receive inhibition from all competing nodes. The activation level of a given competitor, and therefore its inhibitory capacity, is a function of orthographic overlap, with the stimulus on the one hand and frequency (resting level activation) on the other. Stimulus words with higher frequency neighbors will therefore receive more inhibition than will stimulus words with no higher frequency neighbors.

The above explanations of the neighborhood frequency effect all assume that lexical representations other than the stimulus word itself have been activated. If the interference produced by these competing units is related to the degree of activation they attain, then one should be able to observe variations in the magnitude of neighborhood interference by manipulating the hypothetical activation levels of these competitors. In hierarchical models of visual word recognition, such as interactive activation 
(McClelland \& Rumelhart, 1981), the activation levels of word units are directly related to the activation levels of their constituent letters". The activation levels of these letter units are, in turn, presumed to be directly related to the quality of the visual information that describes them. One simple and quite natural means of manipulating the quality of visual information across a string of letters is to vary the position the eye fixates in that string. It is a well-established fact that the quality of visual information is maximal at the point of fixation and drops off rapidly as one moves away from this fixation point. Thus, acuity drops off drastically even within the fovea, so that at its edge (about four to six characters from the fixated character for Times Roman 12-point type held at $30 \mathrm{~cm}$ ), resolution is half that of resolution at its center. Lateral interactions produced by the presence of other letters further worsen the dropoff (see O'Regan, 1989, 1990, for a review of studies pertaining to this issue).

Various measures of the ease of processing isolated words (gaze duration, naming latency, lexical decision speed and accuracy) have also been shown to vary systematically as a function of initial fixation position (Nazir, O'Regan, \& Jacobs, 1991; O'Regan, 1989; O'Regan \& Jacobs, in press; O'Regan \& Lévy-Schoen, 1987; O'Regan, Lévy-Schoen, Pynte, \& Brugaillère, 1984). The result (for latencies) is a U-shaped function, with its minimum (referred to as the optimal viewing position) generally near the center of the word and maxima at the extremities. Recent research by McConkie, Kerr, Reddix, Zola, and Jacobs (1989) and Nazir et al. (1991) has demonstrated that the shape of this function can be accurately predicted by a model where overall word visibility is a simple additive function of the visibility of each component letter. This observation therefore supports hierarchical models of visual word recognition, which suppose that there exists a direct relation between the activation levels of component letters and the activation level of the stimulus word.

Thus, if varying the fixation position in the stimulus word produces variations in the visibility of its component letters, fixated letters being rendered more visible, then fixating the critical or disambiguating letter in a word with one higher frequency neighbor should reduce the interference produced by this neighbor. For example, the French word astre has one higher frequency neighbor, autre. In this case, the critical letter is the letter $s$, and increasing the visibility of this letter should help discriminate astre from its competitor autre in the wordrecognition process. In other words, we predict an interaction between the effects of neighborhood frequency and the position of eye fixation in the stimulus word (on or off the critical disambiguating letter).

\section{EXPERIMENT 1}

Using the lexical decision task to estimate wordrecognition latencies, Experiment 1 tested for neighborhood frequency effects in five-letter words while varying the initial fixation position of the eye in the stimulus word. It was predicted that initially fixating the critical letter of a word with a higher frequency neighbor should reduce the interference produced by this neighbor in the recognition process.

\section{Method}

Subjects. Thirty 3rd-year psychology students at Rene Descartes University, Paris, took part in Experiment 1 for course credit. All were native speakers of French, with normal or corrected-tonormal vision.

Design and Stimuli. Five-letter French words were selected that differed from a more frequent five-letter word by either the second letter (e.g., ASTRE-autre) or the fourth letter (e.g., CHOPE-chose). A total of 14 words were selected for each level of this position-ofambiguity factor. For each of these words, another five-letter word was selected that was matched for frequency (with an average of 23 occurrences per million; see Tresor de la langue Française, 1971), average positional bigram frequency (with an average token frequency of 2,101 occurrences per million), and number of neighbors $(N=3.6)$, but that did not differ from a more frequent word by a single letter (i.e., did not have a higher frequency neighbor). Neighborhood frequency was therefore crossed with position of ambiguity giving a total of 56 word stimuli. Position of initial fixation was also factorially combined with the two preceding factors, such that each stimulus word was presented to different subjects either with the fixation point on the second letter or the fourth letter. For the words with higher frequency neighbors, this therefore corresponded to whether or not the critical disambiguating letter was fixated. Each subject therefore saw each of the stimulus words once only with initial fixation position either on the second letter or the fourth letter. The subjects were also presented with an equal number of five-letter orthographically legal pronounceable nonwords, half of which were fixated initially on the second letter and the other half on the fourth letter. The nonwords were selected such that they differed from one or several real words by a single letter (the average number of word neighbors of the nonword stimuli is 3.6 , which is identical to the value for the word stimuli). The position of letter change with a real word varied across the different nonwords. Thus, the subjects received a total of 112 experimental stimuli.

Procedure. Stimuli were presented in isolation on the center of the display screen of an Olivetti M24 personal computer. The stimuli appeared on the screen as green uppercase characters (with a luminance of approximately $70 \mathrm{~cd} / \mathrm{m}^{2}$ ) on dark background (with a luminance of approximately $5 \mathrm{~cd} / \mathrm{m}^{2}$ ). A five-letter word covered approximately $1.9^{\circ}$ of visual angle from a viewing distance of $60 \mathrm{~cm}$. The subjects saw a fixation mark for $500 \mathrm{msec}$, which then disappeared and was replaced by the stimulus. The fixation mark consisted of two vertical bars situated one line above and one line below the line where the stimulus appeared. The position of the fixation mark remained constant throughout the experiment, and the stimuli appeared with either the second letter or the fourth letter on the fixation mark. The stimulus remained on the screen until the subjects responded either "word" or "nonword" by pressing one of two response buttons. Positive responses were made with the forefinger of the preferred hand, and negative responses with the forefinger of the other hand. The next trial followed after a $1-\mathrm{sec}$ delay. The subjects were instructed to respond as rapidly and accurately as possible. Stimulus presentation was randomized with a different order for each subject. The subjects were given 20 practice trials consisting of a randomly ordered set of 10 word and 10 nonword stimuli, none of which appeared in the experiment proper.

\section{Results}

All reaction times (RTs) exceeding $1,500 \mathrm{msec}$ were excluded from the analysis of the correct responses to word stimuli ( $0.8 \%$ of the data). Means of the lexical decision latencies for correct responses and percent errors 
Table 1

Mean Lexical Decision Latencies (RTs; in Milliseconds) and Percent Errors to the Word Stimuli of Experiment 1

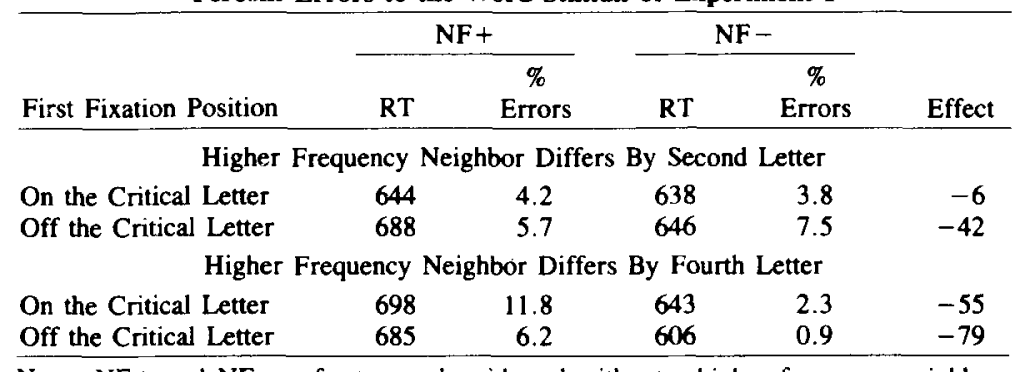

Note-NF + and NF - refer to words with and without a higher frequency neighbor, respectively.

to word stimuli are given in Table 1 . An analysis of variance (ANOVA) was performed on the data with neighborhood frequency (words with or without a higher frequency neighbor), position of ambiguity (second or fourth letter), and first fixation position (on or off the critical letter) as main factors.

The main effect of neighborhood frequency was significant $[F(1,28)=36.48, p<.001]$; words with a higher frequency neighbor were responded to $46 \mathrm{msec}$ more slowly than were words with no higher frequency neighbor. The main effects of position of ambiguity and first fixation position were not significant (both $F_{\mathbf{S}}<1$ ). There was a trend to an interaction between neighborhood frequency and first fixation position $[F(1,28)=3.41$, $p<.10$ ]. This trend reflects the stronger $61-\mathrm{msec}$ effect of neighborhood frequency when fixation was off the ambiguous letter $[F(1,28)=27.89, p<.001]$ relative to the $31-\mathrm{msec}$ effect when fixation was on the ambiguous letter $[F(1,28)=7.68, p<.01]$. The effects of neighborhood frequency significantly interacted with position of ambiguity $[F(1,28)=22.15, p<.001]$, a 67 -msec effect being observed with words that differed from their more frequent neighbor by the fourth letter $[F(1,28)=$ $40.86, p<.001]$ relative to the $24-\mathrm{msec}$ effect observed when the difference was at the second letter $[F(1,28)=$ $10.47, p<.01]$. When first fixation position was redefined as on the second letter or the fourth letter of the stimulus, there was a significant effect of this factor, with RTs 26 msec faster when initial fixation was on the second letter $[F(1,28)=7.70, p<.01]$.

An analysis of the error data indicated that more errors were made to words that had a higher frequency neighbor $[F(1,28)=10.44, p<.01]$. The effects of neighborhood frequency interacted with position of ambiguity $[F(1,28)=12.33, p<.01]$, the effects of neighborhood interference being significant only for words whose higher frequency neighbor differed by the fourth letter $[F(1,28)$ $=22.05, p<.001]$. None of the other interactions were significant. Fewer errors were made when initial fixation was on the second letter than when initial fixation was on the fourth letter $[F(1,28)=6.88, p<.05]$.

An analysis of responses to the nonword stimuli (using a 1,500 -msec cutoff, eliminating $4.2 \%$ of the data) showed that significantly faster RTs were obtained when fixation was on the fourth letter $(780 \mathrm{msec})$ than when fixation was on the second letter $(806 \mathrm{msec})[F(1,28)=5.74$, $p<.05]$. Similarly, significantly fewer errors occurred when fixation was on the fourth letter $(6.3 \%)$ than when fixation was on the second letter $(11.1 \%)[F(1,28)=$ $10.15, p<.01]$.

\section{Discussion}

The results of Experiment 1 replicate previous observations of neighborhood frequency effects for words with only one higher frequency neighbor (Grainger, 1990; Grainger et al., 1989). Moreover, as predicted, this effect was shown to be affected by whether or not the eye first fixates the critical letter distinguishing the stimulus from its more frequent neighbor. Initially fixating the critical disambiguating letter of a word with a higher frequency neighbor reduced the observed interference to about half of that observed when fixation was off the disambiguating letter. The critical interaction did not, however, reach the conventional level of statistical significance.

The further observation that RT and error rates diminished when the eye initially fixates the second letter as opposed to the fourth letter of a five-letter word supports previous observations of improved word-recognition performance when the eye initially fixates a position just left of the middle of the word (O'Regan \& Jacobs, in press; O'Regan \& Lévy-Schoen, 1987; O'Regan et al., 1984; Vitu, O'Regan, \& Mittau, 1990). However, the asymmetry has been most pronounced in long (seven letters or more), low-frequency words, and previous data for shorter words has been less obviously asymmetric. The results of Experiment 1 provide some evidence that this asymmetry is affected by the neighborhood characteristics of the stimuli. For the words with higher frequency neighbors, the second-letter advantage was greatly diminished (13 msec) when critical information was situated at the fourth letter (i.e., the $P$ in CHOPE) relative to the $44-\mathrm{msec}$ advantage when critical information was at the second letter (i.e., the $s$ in ASTRE). However, the critical three-way interaction (first fixation position $\times$ neighborhood frequency $\times$ position of ambiguity) in support of the observed differences in the means was not significant. 
Finally, the significant interaction between neighborhood frequency and position of ambiguity demonstrates that five-letter words differing from a more frequent word by their second letter (ASTRE-AUTRE) are less prone to interference than are words differing from a more frequent word by their fourth letter (CHOPE-CHOSE). This result suggests that word beginnings play a privileged role in the process of visual word recognition. If the initial letters of a word are in some way given priority in the process of visual word recognition, then potential ambiguities that occur in the beginning part of a word will be resolved more rapidly than will those that occur at the end of the word.

The observed advantage for fixating the second letter as opposed to the fourth letter of word stimuli can also be interpreted as reflecting some form of word-initial bias in the recognition process. Within the framework of hierarchical activation models (McClelland \& Rumelhart, 1981; Paap et al., 1982), the beginning letters of words could provide greater activation input to the word level than the input provided by end letters. Thus, fixating the beginning of a word would provide a greater increase in activation of that word's representational node than would fixating the end. The fact that the nonword stimuli show exactly the opposite pattern of effects (an advantage for fixating the fourth letter) can also be accommodated within this general perspective. It has previously been observed that nonword decision latencies are strongly related to the similarity of the nonword to real words (Andrews, 1989; Coltheart, Davelaar, Jonasson, \& Besner, 1977). These results have been interpreted as evidence that the more a given nonword activates lexical representations, the harder it is to reject this nonword in the lexical decision task (Coltheart et al., 1977). Fixating the beginning of a nonword would cause a greater rise in activation of lexical representations than would fixating the end, and it would therefore lead to longer rejection latencies and a greater number of errors.

\section{EXPERIMENT 2}

Experiment 1 provided partial support for our initial hypothesis concerning the interaction between neighbor- hood frequency effects and the position the eye initially fixates the stimulus word. The absence of a significant interaction may be partly due to the subjects' making more than one fixation on the stimulus before responding in the lexical decision task. In this case, the subjects would be fixating the critical letter during only part of the wordrecognition process. To avoid this, stimulus-presentation duration was reduced in Experiment 2. It is currently assumed that subjects do not have sufficient time to make a second fixation on the stimulus when presentation durations are less than $170 \mathrm{msec}$ (e.g., see O'Regan, 1990). In these conditions, subjects are forced to use only information gathered from the stimulus during the initial fixation in order to make their lexical decision.

\section{Method}

Subjects. Thirty third-year psychology students at Rene Descartes University, Paris, took part in Experiment 2 for course credit. All were native speakers of French, with normal or corrected-to-normal vision and had not participated in Experiment 1.

Design and Stimuli. The design and stimuli of Experiment 2 were identical to those of Experiment 1.

Procedure. The procedure differed from Experiment 1 in the following manner. Stimulus-presentation duration was limited to $160 \mathrm{msec}$. The stimulus was immediately followed by a backward pattern mask of five hash marks (\#\#\#\#), which remained on the screen until the subject responded.

\section{Results}

All RTs exceeding 1,500 msec were excluded from the analysis of the correct responses to word stimuli $(0.3 \%$ of the data). Means of the lexical decision latencies for correct responses and percent errors are given in Table 2. An ANOVA was performed on the data, as in Experiment 1 , with neighborhood frequency (words with or without a higher frequency neighbor), position of ambiguity (second or fourth letter), and first fixation position (on or off the critical disambiguating letter) as main factors.

There was a significant main effect of neighborhood frequency $[F(1,28)=6.03, p<.05]$. The effect of neighborhood frequency interacted with position of ambiguity $[F(1,28)=11.17, p<.01]$ but did not interact with first fixation position $[F(1,28)=2.33]$. The interaction between neighborhood frequency and position of ambiguity reflects the fact that neighborhood interference

Table 2

Mean Lexical Decision Latencies (RTs; in Milliseconds) and Percent Errors to the Word Stimuli of Experiment 2 Using Reduced Stimulus-Presentation Times

\begin{tabular}{|c|c|c|c|c|c|}
\hline \multirow[b]{2}{*}{ First Fixation Position } & \multicolumn{2}{|c|}{ NF+ } & \multicolumn{2}{|c|}{ NF- } & \multirow[b]{2}{*}{ Effect } \\
\hline & RT & $\begin{array}{c}\% \\
\text { Errors }\end{array}$ & RT & $\begin{array}{c}\% \\
\text { Errors }\end{array}$ & \\
\hline \multicolumn{6}{|c|}{ Higher Frequency Neighbor Differs By Second Letter } \\
\hline $\begin{array}{l}\text { On the Critical Letter } \\
\text { Off the Critical Letter }\end{array}$ & $\begin{array}{l}403 \\
460\end{array}$ & $\begin{array}{r}9.1 \\
13.8\end{array}$ & $\begin{array}{l}412 \\
460\end{array}$ & $\begin{array}{r}7.1 \\
14.6\end{array}$ & $\begin{array}{r}+9 \\
0\end{array}$ \\
\hline \multicolumn{6}{|c|}{ Higher Frequency Neighbor Differs By Fourth Letter } \\
\hline $\begin{array}{l}\text { On the Critical Letter } \\
\text { Off the Critical Letter }\end{array}$ & $\begin{array}{l}457 \\
456\end{array}$ & $\begin{array}{l}16.2 \\
15.2\end{array}$ & $\begin{array}{l}440 \\
416 \\
\end{array}$ & $\begin{array}{r}11.9 \\
8.6\end{array}$ & $\begin{array}{l}-17 \\
-40\end{array}$ \\
\hline
\end{tabular}

Note-NF + and NF - refer to words with and without a higher frequency neighbor, respectively. 
was significant only for the words whose higher frequency neighbor differed by the fourth letter $[F(1,28)=17.05$, $p<.01]$. The triple interaction was not significant $(F<1)$.

Although the interaction between neighborhood frequency and first fixation position was not significant, an examination of the data for the words whose higher frequency neighbors differed by the fourth letter and the corresponding controls indicates that neighborhood interference appears to have been modified by first fixation position here. When the eye initially fixates the second letter of the stimulus, there was a significant 40 -msec effect of neighborhood interference $[F(1,28)=18.15$, $p<.001]$. On the other hand, when initial fixation position was on the fourth (i.e., critical) letter, the effects of neighborhood interference were reduced to a nonsignificant $17 \mathrm{msec}[F(1,28)=3.04]$. The interaction was not, however, significant $[F(1,28)=1.24]$.

As with Experiment 1, when first fixation position was redefined as on the second letter or the fourth letter of the stimulus, responses to words are $32 \mathrm{msec}$ faster when initial fixation was on the second letter $[F(1,28)=13.81$, $p<.01]$. This second-letter advantage significantly interacted with position of ambiguity $[F(1,28)=4.81, p<$ $.05]$. When conditioned by the factor neighborhood frequency, however, this interaction was significant only for the words with higher frequency neighbors $[F(1,28)=$ $4.97, p<.05]$. There was a significant 57 -msec advantage for fixating the second letter of a word whose higher frequency neighbor differed by the second letter $[F(1,28)=$ $16.42, p<.001]$ and a nonsignificant $1-\mathrm{msec}$ advantage for fixating the second letter of a word whose higher frequency neighbor differed by the fourth letter $(F<1)$.

The error data in Table 2 show the same general pattern of effects as the RT data. An ANOVA indicated that none of the main effects reached statistical significance. Nevertheless, as with the RT data, neighborhood frequency interacted with position of ambiguity $[F(1,28)=4.56$, $p<.05]$. Neighborhood frequency effects were significant only for words whose higher frequency neighbor differed by the fourth letter $[F(1,28)=15.56, p<.001]$. None of the other interactions were significant.

An analysis of responses to the nonword stimuli (using a 1,500-msec cutoff, eliminating $1.6 \%$ of the data) showed the same pattern of results as in Experiment 1. Significantly faster RTs were obtained when fixation was on the fourth letter $(546 \mathrm{msec})$ than when fixation was on the second letter $(577 \mathrm{msec})[F(1,28)=8.37, p<.01]$. Similarly, significantly fewer errors occurred when fixation was on the fourth letter $(12.7 \%)$ than when fixation was on the second letter $(20.5 \%)[F(1,28)=17.02$, $p<.001]$.

\section{Discussion}

The results of Experiment 2 replicate the principal results obtained in Experiment 1. Neighborhood interference was observed only for words whose higher frequency neighbor differed by the fourth letter (e.g., CHOPE). Also, lexical decision latencies were faster when initial fixation was imposed on the second letter than when initial fixation was imposed on the fourth letter. This advantage for initially fixating the second letter of a five-letter word disappeared, however, when the stimulus had a higher frequency neighbor differing by the fourth letter. In other words, fixating the $\mathrm{H}$ in CHOPE did not facilitate recognition relative to when initial fixation position was on the P. With these CHOPE-type words, strong neighborhood interference is observed when fixation is on the second letter and this interference is greatly diminished when fixation is on the fourth (i.e., critical) letter. Thus, the usual advantage for fixating the second letter of a five-letter word is canceled here by the increased neighborhood interference. This result therefore suggests that, as predicted, fixating the critical disambiguating letter of a word with a higher frequency neighbor does reduce the competitiveness of that neighbor. Nevertheless, as in Experiment 1, the critical interactions supporting such a conclusion are not significant.

\section{COMBINED ANALYSIS OF EXPERIMENTS 1 AND 2}

In view of the fact that some critical two- and threeway interactions failed to reach statistical significance in Experiments 1 and 2, we decided to perform a joint ANOVA of the RT and error data of the word stimuli from both experiments. This simply involved adding a between-subject factor, stimulus duration (unlimited in Experiment 1 and $160 \mathrm{msec}$ in Experiment 2).

This joint analysis showed that there were significantly faster RTs $[F(1,56)=97.25, p<.001]$ and more errors $[F(1,56)=15.68, p<.001]$ with the shorter stimulus durations of Experiment 2. The main effect of neighborhood frequency was significant in both the RT data $[F(1,56)=37.04, p<.001]$ and the error data $[F(1,56)$ $=11.33, p<.01]$. These two factors significantly interacted in the RT analysis $[F(1,56)=8.21, p<.01]$, indicating that neighborhood interference effects are stronger with unlimited stimulus duration. Stimulus duration did not interact with any of the other effects. These other main and interaction effects will therefore be considered, averaging over both experiments. The most relevant of these are shown in Figure 1, which provides the net inhibitory effects of neighborhood frequency on RT averaging over Experiments 1 and 2.

When defined as on or off the critical disambiguating letter, first fixation position did not have a significant main effect either on RTs $[F(1,56)=2.88]$ or errors $(F<1)$. More importantly, however, the interaction between neighborhood frequency and first fixation position was now significant in the RT analysis $[F(1,56)=5.41$, $p<.05]$. The effects of neighborhood frequency were more than twice as large ( $41 \mathrm{msec}$ vs. $18 \mathrm{msec}$ ) when the 


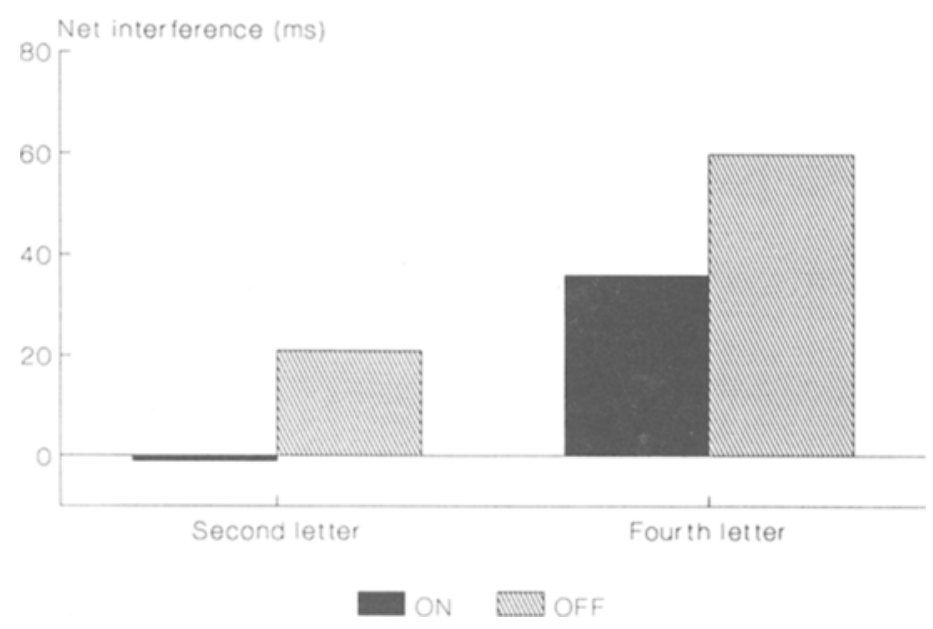

Figure 1. Net inhibitory effects of neighborhood interference (as estimated from control words with no higher frequency neighbors) on RTs averaged over Experiments 1 and 2. Words with a higher frequency neighbor differed from this neighbor by either the second letter (e.g., ASTRE) or the fourth letter (e.g., CHOPE) and initial fixation position was either on or off the critical disambiguating letter.

eye did not fixate the critical disambiguating letter. This interaction in the RT data is reflected in Figure 1 by the difference between columns 1 and 3 and columns 2 and 4 .

The effect of position of ambiguity was not significant ( $F<1$, for both RTs and errors), but this factor significantly interacted with neighborhood frequency in both the $\mathrm{RT}$ analysis $[F(1,56)=28.82, p<.001]$ and the error analysis $[F(1,56)=15.89, p<.001]$. Neighborhood frequency only produced significant interference effects in RTs $[F(1,56)=56.66, p<.001]$ and errors $[F(1,56)=$ $37.59, p<.001]$ for words that differed from their higher frequency neighbor by the fourth letter. This inter- action is represented in Figure 1 by the difference between the two leftmost columns and the two rightmost columns.

When first fixation position was defined as on the second or the fourth letter, there was a significant main effect of this factor on both RTs $[F(1,56)=20.76, p<.001]$ and errors $[F(1,56)=8.47, p<.01]$. Lexical decision latencies were $29 \mathrm{msec}$ faster when initial fixation was on the second letter than when it was on the fourth letter. The three-way interaction between neighborhood frequency, first fixation position, and position of ambiguity is now significant in the $\mathrm{RT}$ analysis $[F(1,56)=5.41, p<.05]$. This triple interaction is principally a reflection of the vari-

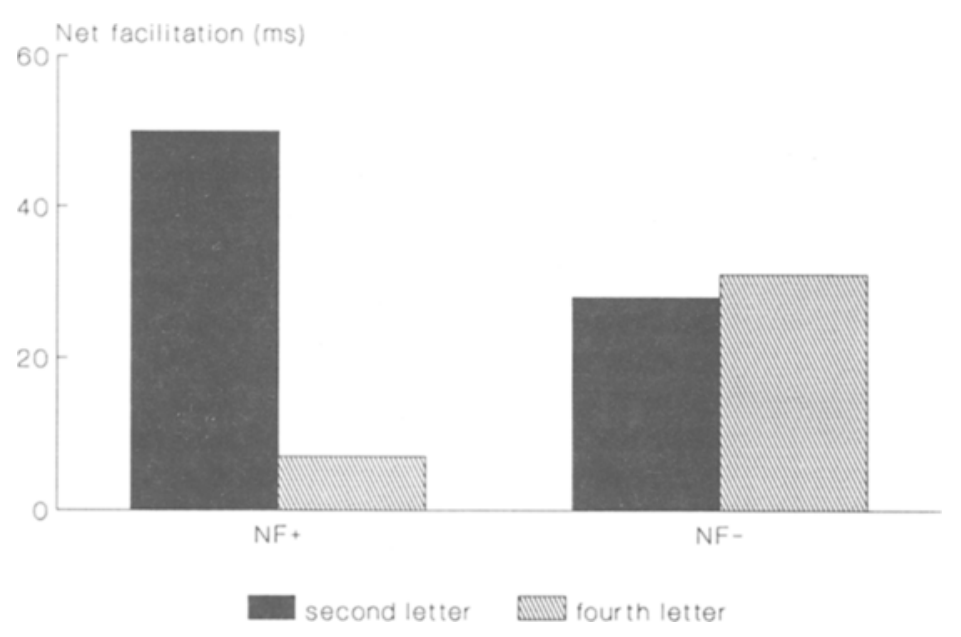

Figure 2. Net RT advantage for initially fixating the second letter, as opposed to the fourth letter, of five-letter words with a higher frequency orthographic neighbor $(\mathrm{NF}+)$ and the corresponding controls (NF-). The words with a higher frequency neighbor differed from this neighbor by either the second letter (e.g., ASTRE) or the fourth letter (e.g., CHOPE). 
ations in the second-letter advantage (better performance when fixating the second, as opposed to the fourth, letter of the stimulus word) across the other experimental conditions. This interaction is represented in Figure 2.

In Figure 2, the net second-letter advantage (RT when fixating the second letter subtracted from RT when fixating the fourth letter of a stimulus word) is given for the different combinations of neighborhood frequency and position of ambiguity. When words had no higher frequency neighbors, there was a stable second-letter advantage of about $30 \mathrm{msec}$. When the stimuli did have a higher frequency neighbor, however, the second-letter advantage was increased by $22 \mathrm{msec}$ when this letter corresponded to the critical disambiguating letter in the word and was decreased by $24 \mathrm{msec}$ when the fourth letter was critical. This two-way interaction was significant $[F(1,56)=$ $5.82, p<.05]$.

\section{GENERAL DISCUSSION}

The present experiments replicate the basic neighborhood frequency effect reported by Grainger et al. (1989) and show that when the stimulus word has a single higher frequency neighbor, the position of letter change between the stimulus word and this higher frequency neighbor is critical in determining the observed interference. More precisely, words that differ from a more frequent word by the fourth letter (e.g., CHOPE-CHOSE) showed strong interference effects, whereas words that differ by the second letter (e.g., ASTRE-AUTRE) did not show significant interference. The results also replicate a fundamental characteristic of the optimal viewing position phenomenon reported by O'Regan et al. (1984)-namely, that varying initial fixation position left and right from the middle of a stimulus word does not produce a symmetric variation in ease of word recognition. Word recognition was systematically facilitated when fixation was on the second letter of a five-letter word relative to when fixation was on the fourth letter.

More importantly, the present results are an example of how visual and lexical factors interact in visual word recognition. This interaction is evident in two different, but related, aspects of the data illustrated in Figures 1 and 2. First, when subjects initially fixate the critical disambiguating letter of a word with a more frequent orthographic neighbor (e.g., the letter P in CHOPE), interference effects are significantly reduced relative to when initial fixation is off this critical letter (see Figure 1). Second, the observed improvement in word-recognition performance when fixation was on the second letter, rather than the fourth letter, of the five-letter word stimuli in the present experiments practically disappears when the word in question contains critical information at the fourth letter (i.e., information that distinguishes it from a more frequent orthographically similar word; see Figure 2). Thus, these results strongly suggest that, on the one hand, the effects of competition between lexical representations can be modified by the relative visibility of the stimulus word's letters and, on the other hand, that the distribu- tion of lexically constraining information across the stimulus word influences the consequences of varying the relative visibility of the component letters.

To accommodate the complete set of results obtained in the present experiments, activation-based models of visual word recognition (McClelland \& Rumelhart, 1981; Paap et al., 1982) must introduce sequential-like properties in what is otherwise a basically parallel uptake of information. In other words, although these models can continue to maintain that, to a certain extent, all letters in a word are processed simultaneously, they must attribute more weight to the processing of initial, as opposed to final, letters. Initial letters could provide more activation at the level of lexical representations and/or lexical representations could provide more facilitatory feedback to their initial letters. In this case, increasing the visibility of initial letters by imposing initial fixation on the second letter would increase the activation levels of initial letters, thus causing a relatively greater increase in activation at the word level than when end letters are rendered more visible. This would account for the observed advantage for initially fixating the second letter of a fiveletter word, relative to initially fixating the fourth letter.

Assigning greater weight to the connections between initial letters and word representations than to the connections between end letters and the same representations can account for the pattern of neighborhood frequency effects observed here. If word-initial letters produce a greater rise in activation of lexical representations than do word-final letters, it is conceivable that the difference in activation level of a competing pair such as ASTREAUTRE might be less than the difference in activation level of a competing pair such as CHOPE-CHOSE. Since the stimulus ASTRE differs from its high-frequency competitor AUTRE by the second letter, this competitor would be receiving less activation from sublexical levels than would the competitor CHOSE during the processing of the stimulus CHOPE. If total interference on the stimulus word is a function of the activation level of its closest competitor, this biased-weighting procedure can account for the pattern of neighborhood effects observed. In the interactiveactivation model (McClelland \& Rumelhart, 1981) and in a modified version of activation verification (Grainger \& Segui, 1990; Segui \& Grainger, 1990), the activation level of the stimulus word's strongest competitor (when there is only one strong competitor) is critical in determining interference. Increasing the activation level of this competitor increases total inhibition on the stimulus word in the interactive-activation model and increases the probability of this representation reaching the verification threshold in the modified activation-verification model. Thus, both models can accommodate the present results if one adds a word-initial bias in the sublexical-to-lexical connection strengths. With further developments in the implementation of these models, it should be possible to provide a more thorough test of the mechanisms that they embody.

The present results therefore argue for the presence of some form of sequential bias in the visual word-recognition process. One possible source of this bias is the fact that 
the majority of words are first learned in the auditory modality where a left-to-right processing of sensory information is imposed. Another phenomenon directly related to this bias is the observation that the eye tends to preferentially fixate the initial part of words (Dunn-Rankin, 1978; McConkie, Kerr, Reddix, \& Zola, 1988; Rayner, 1979). Whether this preferred fixation position is a source of, or the result of, the type of sequential bias observed in the present experiments remains to be examined in future experimentation. If this bias renders words more easily recognizable when fixating near the beginning, the preferred fixation position may well reflect a strategy developed to maximize reading efficiency. On the other hand, if readers (and more specifically, beginning readers) tend to fixate the beginnings of words for purely oculomotor reasons, this would affect the way words are encoded in memory when learning to read and could therefore provide the basis of the sequential bias observed here.

\section{REFERENCES}

ANDREWs, S. (1989). Frequency and neighborhood effects on lexical access: Activation or search? Journal of Experimental Psychology: Learning, Memory, \& Cognition, 15, 802-814.

Coltheart, M., Davelaar, E., Jonasson, J. T., \& Besner, D. (1977). Access to the internal lexicon. In S. Dornic (Ed.), Attention and performance $V I$ (pp. 535-555). Hillsdale, NJ: Erlbaum.

DUNN-RANkin, P. (1978). The visual characteristics of words. Scientific American, 238(1), 122-130.

GRAINGER, J. (1990). Word frequency and neighborhood frequency effects in lexical decision and naming. Journal of Memory \& Language, 29, 228-244.

Grainger, J., O'Regan, J. K., Jacobs, A. M., \& Segui, J. (1989). On the role of competing word units in visual word recognition: The neighborhood frequency effect. Perception \& Psychophysics, 45, 189-195.

GraINGER, J., \& SEGUI, J. (1990). Neighborhood frequency effects in visual word recognition: A comparison of lexical decision and masked identification latencies. Perception \& Psychophysics, 47, 191-198.

Grainger, J., \&egUI, J. (1991). Priming word recognition with orthographic neighbors: Effects of nonword primes. Manuscript submitted for publication.

LuCE, P. A. (1986). Neighborhoods of words in the mental lexicon. Unpublished doctoral dissertation, Indiana University, Bloomington.

Luce, P. A., Pisoni, D. B., \& Goldinger, S. D. (1990). Similarity neighborhoods of spoken words. In G. Altmann (Ed.), Cognitive models of speech processing: Psycholinguistic and computational perspectives (pp. 122-147). Cambridge, MA: MIT Press.

McClelland, J. L., \& Rumelhart, D. E. (1981). An interactiveactivation model of context effects in letter perception. Part 1. An account of basic findings. Psychological Review, 88, 375-405.

McConkIe, G. W., Kerr, P. W., Reddix, M. D., ZoLA, D. (1988). Eye movement control during reading: $I$. The location of initial eye fixations on words. Vision Research, 28, 1107-1118.

McConkie, G. W., Kerr, P. W., Reddix, M. D., ZolA, D., \& JACOBS, A. M. (1989). Eye movement control during reading: II. Frequency of refixating a word. Perception \& Psychophysics, 46, 245-253.

Nazir, T. A., O'Regan, J. K., Jacobs, A. M. (1991). On words and their letters. Bulletin of the Psychonomic Society, 29, 171-174.

O'REGAN, J. K. (1989). Visual acuity, lexical structure, and eye movements in word recognition. In B. Elsendoorn \& H. Bouma (Eds.), Working models of human perception (pp. 261-292). London: Academic Press.

OREGAN, J. K. (1990). Eye movements and reading. In E. Kowler (Ed.), Eye movements and their role in visual and cognitive processes (pp. 395-453). Amsterdam: Elsevier.

O'RegAN, J. K., JACOBS, A. M. (in press). The optimal viewing position effect in word recognition: A challenge to current theory. Joumal of Experimental Psychology: Human Perception \& Performance.

O'REgAN, J. K., \& LÉVY-SCHOEN, A. (1987). Eye movement strategy and tactics in word recognition and reading. In M. Coltheart (Ed.), Attention and performance XII: The psychology of reading (pp. 363384). Hillsdale, NJ: Erlbaum.

O'Regan, J. K., Lévy-Schoen, A., Pynte, J., Brugaillère, B. (1984). Convenient fixation location within isolated words of different length and structure. Jourmal of Experimental Psychology: Human Perception \& Performance, 10, 250-257.

PaAP, K. R., Newsome, S. L., McDonald, J. E., \& SchVaneveldt, R. W. (1982). An activation-verification model for letter and word recognition: The word superiority effect. Psychological Review, 89, 573-594.

RAYNER, K. (1979). Eye guidance in reading: Fixation locations within words. Perception, 8, 21-30.

Segui, J., \& GraInger, J. (1990). Priming word recognition with orthographic neighbors: Effects of relative prime-target frequency. Journal of Experimental Psychology: Human Perception \& Performance, 16, 65-76.

Trésor de la langue Française (1971). Nancy: C.N.R.S.

Vitu, F., O'Regan, J. K., Mittau, M. (1990). Optimal landing position in reading isolated words and continuous text. Perception \& Psychophysics, 47, 583-600.

(Manuscript received February 13, 1991; revision accepted for publication August 9, 1991.) 